\title{
High-frequency oscillatory ventilation and acute respiratory distress syndrome: at the crossroads?
}

\author{
Matt P Wise, ${ }^{1}$ Anton G Saayman, ${ }^{1}$ Michael A Gillies ${ }^{2}$
}

Acute respiratory distress syndrome (ARDS) was characterised by Ashbaugh and colleagues ${ }^{1}$ nearly half a century ago, and yet, to the casual observer, it might appear that little progress has been made since. Clinicians are still struggling with how best to define and treat ARDS. ${ }^{2}{ }^{3} \mathrm{~A}$ major advance was the recognition that mechanical ventilation may induce further lung injury and the application of socalled lung protective ventilation $(6 \mathrm{ml} / \mathrm{kg}$ ideal body weight tidal volumes and plateau pressures $<30 \mathrm{~cm} \mathrm{H}_{2} \mathrm{O}$ ) reduces mortality. ${ }^{4}$ High-frequency oscillatory ventilation (HFOV) is an attractive mode of ventilation because it combines improved lung recruitment with small tidal volumes, often below anatomical dead space, applied at very high frequency. Thus, it theoretically provides ultra-lung protective ventilation, limiting atelectrauma (caused by cyclical alveolar opening and closing) and volutrauma (alveolar over-distension). For those not familiar with this mode of ventilation, it should be noted that, unlike conventional ventilation, increasing the frequency of HFOV reduces $\mathrm{CO}_{2}$ elimination. HFOV has often been used as a rescue therapy for severe ARDS and refractory hypoxaemia; however, uncertainty remains over its role in early ARDS. Although there is substantial experimental data, clinical studies are limited to case series and two small trials ${ }^{5} 6$ where controls did not receive what is now accepted as standard lung protective ventilation following the ARDSNet study. ${ }^{4}$

Two recently randomised clinical trials sought to establish if HFOV could reduce mortality in early ARDS. ${ }^{7}$ The UK-based OSCAR study ${ }^{7}$ randomised 795 patients to receive either HFOV or conventional

\footnotetext{
${ }^{1}$ Adult Critical Care, University Hospital of Wales, Cardiff, UK; ${ }^{2}$ Department of Anaesthesia, Critical Care and Pain Medicine, Royal Infirmary of Edinburgh, Edinburgh, UK

\section{Correspondence to}

Dr Matt P Wise, Adult Critical Care, University Hospital of Wales, Cardiff CF14 4XW, UK; mattwise@doctors. org.uk
}

ventilation. No difference was observed in 30 day mortality between groups $(41.7 \%$ vs $41.1 \%$, respectively). The larger OSCILLATE study ${ }^{8}$ planned to recruit 1200 patients but was stopped after 548 patients on recommendation from the data monitoring committee, as in-hospital mortality was significantly higher in those assigned to HFOV (47\% vs 35\%). Recruitment was broadly similar in both trials, which aimed to enrol patients with early ARDS and a $\mathrm{PaO}_{2} / \mathrm{FiO}_{2}$ $\leq 200 \mathrm{~mm} \mathrm{Hg}$ rather than using HFOV as a rescue therapy. From these trials, it would appear that HFOV does not improve mortality in early ARDS, and at worse, might be harmful. However, although ostensibly both trials applied a similar intervention to a similar group of patients, there were significant differences between studies and also in how this technology was applied in UK Intensive Care Units prior to publication of these studies. The major differences between studies are summarised in tables 1 and 2 .

\section{VENTILATOR SELECTION}

For the past two decades, adult HFOV in Europe and North America has largely been undertaken using the SensorMedics 3100B oscillator (CareFusion). The OSCAR trial chose to use the Novalung R100 ventilator (Metran) device which, despite having been used in Japan, was relatively untried in the UK and had only been awarded a CE mark shortly before the start of the study. All 25 critical care units in the UK providing HFOV prior to the trial used the SensorMedics 3100B oscillator $^{7}$; no explanation was given for choosing this unfamiliar equipment.

\section{CENTRE SELECTION}

Centre characteristics can be an important determinant of outcome in mechanical ventilation as intensive care units dealing with higher caseloads have better outcomes. ${ }^{9}$ HFOV can be a complex intervention, with centres building up experience in its use over several years. ${ }^{10}$ OSCILLATE used 39 centres, predominantly North American hospitals with previous experience of HFOV employing the $3100 \mathrm{~B}$ oscillator. In OSCAR, only 3 centres had significant experience of HFOV, 6 had limited experience and the remaining 20 had none. No centre had used the Novalung R100 previously and a substantial effort was put into training over 2300 clinical staff. Lack of equipoise is likely to have existed in the UK centres with substantial prior HFOV experience. The inability to use HFOV as a rescue therapy in the OSCAR trial is likely to have contributed to this. In OSCILLATE, 34 patients in the control group received HFOV (31 in accordance with the trial protocol); however, neither trial specifically recorded the use of HFOV outside of the trial in the severe ARDS subgroup.

\section{PARTICIPANT SELECTION}

Each trial broadly included similar patients; it is, however, notable that APACHE II scores were significantly higher in the OSCILLATE study (29 vs 21.8). In OSCAR, inclusion was dependent on the onset of mechanical ventilation within the previous 7 days, but up to 14 days of respiratory failure were permitted in OSCILLATE. Patients were included if the $\mathrm{PaO}_{2} / \mathrm{FiO}_{2}$ was $\leq 200 \mathrm{~mm} \mathrm{Hg}$ on a PEEP of $\geq 5 \mathrm{~cm} \mathrm{H}_{2} \mathrm{O}^{5}$ or $\mathrm{FIO}_{2} \geq 0.5$ irrespective of PEEP $^{8}$ The OSCILLATE trial used an additional step of standardised ventilator settings for $30 \mathrm{~min}\left(\mathrm{FIO}_{2} \geq 0.6\right.$, PEEP of $\geq 10 \mathrm{~cm} \mathrm{H}_{2} \mathrm{O}$ and tidal volume $6 \mathrm{ml} / \mathrm{kg}$ predicted weight) to reassess if $\mathrm{PaO}_{2} / \mathrm{FiO}_{2}$ was still $\leq 200 \mathrm{~mm} \mathrm{Hg}$, but this excluded only 19 individuals.

\section{VENTILATION PROTOCOL}

Ventilation strategies in these two studies were very different for HFOV and conventional ventilation arms (table 2). OSCILLATE adopted an 'open lung' approach from the outset by using recruitment manoeuvres in both arms. Following this, the smallest tidal volumes for either HFOV or conventional ventilation were applied, aiming for a $\mathrm{pH}>7.25$. The oscillation strategy was based on a round-table discussion of experts in HFOV. ${ }^{11}$ Target oxygen saturations were $88-93 \%$ and were achieved using mean airway pressure-inspired oxygen charts, which in the conventional arm, were based on a previous trial. ${ }^{12}$ Recruitment manoeuvres were mandated frequently with increases in mean airway pressure (HFOV arm) or PEEP (conventional arm) within defined safety parameters. Importantly, cross-over to the other arm of the study could occur as a rescue intervention in refractory hypoxaemia. In contrast, OSCAR did not mandate recruitment manoeuvres in 
Table 1 Overview of OSCILLATE and OSCAR

\begin{tabular}{|c|c|c|}
\hline Intervention & OSCILLATE & OSCAR \\
\hline Oscillator & $\begin{array}{l}\text { SensorMedics } \\
\text { 3100B oscillator (CareFusion) }\end{array}$ & Novalung R100 (Metran) \\
\hline Distribution & Extensively used in North America and Europe & $\begin{array}{l}\text { Extensively used in Japan, not used in Europe or North } \\
\text { America }\end{array}$ \\
\hline I:E ratio & $\begin{array}{l}\text { Usually used with } 1: 2 \mathrm{l}: \mathrm{E} \\
\text { Which may lead to lower pressures in alveoli than measured on oscillator }\end{array}$ & Fixed I:E 1:1 \\
\hline Modes & $\begin{array}{l}\text { HFOV mode only-transition to conventional ventilation requires swapping } \\
\text { ventilators }\end{array}$ & HFOV, PCV, VCV, PSV, CPAP \\
\hline \multirow[t]{3}{*}{ Centres } & 39—mainly North America (35) & 29 UK \\
\hline & Previously used HFOV & 20 no HFOV experience, 6 limited \\
\hline & $\begin{array}{l}\text { Enrolled if } \mathrm{PaO}_{2} / \mathrm{FiO}_{2} \leq 200 \mathrm{~mm} \mathrm{Hg} \text { on a } \mathrm{FIO}_{2} \geq 0.5 \text { irrespective of PEEP } \\
\text { Randomised if } \mathrm{PaO}_{2} / \mathrm{FiO}_{2} \leq 200 \mathrm{~mm} \mathrm{Hg} \text { after } 30 \mathrm{~min} \text { on standard settings } \\
\left(\mathrm{FIO}_{2} \geq 0.6 \text {, PEEP of } \geq 10 \mathrm{~cm} \mathrm{H} \mathrm{H}_{2} \mathrm{O} \text { and tidal volume } 6 \mathrm{ml} / \mathrm{kg}\right)\end{array}$ & $\begin{array}{l}\text { Randomised if } \mathrm{PaO}_{2} / \mathrm{FiO}_{2} \leq 200 \mathrm{~mm} \mathrm{Hg} \text { on a PEEP of } \\
\geq 5 \mathrm{~cm} \mathrm{H} \mathrm{H}_{2} \mathrm{O}\end{array}$ \\
\hline $\begin{array}{l}\text { Recruitment } \\
\text { manoeuvres }\end{array}$ & Mandated in protocol & Maybe used not mandated \\
\hline Cross-over to HFOV & Permitted & Not permitted \\
\hline Mortality & $\begin{array}{l}47 \% \text { HFOV vs } 35 \% \text { control } \\
\text { In hospital }\end{array}$ & $41.7 \%$ HFOV vs $41.1 \%$ conventional ventilation at 30 days \\
\hline
\end{tabular}

HFOV, high-frequency oscillatory ventilation.

either arm of the trial and allowed ventilation in the conventional limb according to local practice but encouraged lung protective ventilation and setting of PEEP and inspired oxygen according to ARDSNet.

This lack of protocolised ventilation in the control arm of the OSCAR study may explain the large disparity in mortality in conventional ventilation groups between trials (table 2), especially as patients in OSCILLATE had higher APACHE II scores. Tidal volumes were also much lower in OSCILLATE; a recent observational study of ARDS found that nonadherence to tidal volumes of $<6.5 \mathrm{ml} / \mathrm{kg}$ ideal body weight increased absolute mortality by $7.8 \%$ at 2 years. ${ }^{13}$ Failure to adhere to lung protective ventilation (30\%) was also a feature of a recent UK trial comparing extracorporeal membrane oxygenation with conventional ventilation. ${ }^{14}$ It is conceivable that had the OSCAR trial achieved tidal volumes approaching $6 \mathrm{ml} / \mathrm{kg}$

Table 2 Delivery of ventilation in OSCILLATE and OSCAR (SD in brackets, ventilation parameters at day 1)

\begin{tabular}{|c|c|c|}
\hline HFOV & OSCILLATE & OSCAR \\
\hline Initial mean airway pressure settings & Mean airway pressure $30 \mathrm{~cm} \mathrm{H}_{2} \mathrm{O}$ & $5 \mathrm{~cm} \mathrm{H}_{2} \mathrm{O}$ above plateau pressure at randomisation \\
\hline Target & $\begin{array}{l}\mathrm{SaO}_{2} 88-93 \% \\
\mathrm{pH} 7.25-35\end{array}$ & $\begin{array}{l}\mathrm{PaO}_{2} 8-10 \mathrm{kPa} \\
\mathrm{pH}>7.25\end{array}$ \\
\hline I:E ratio & $1: 2$ & $1: 1$ \\
\hline pH adjustment & Primarily by adjusting frequency & Primarily by adjusting cycle volume \\
\hline Oxygenation adjustment & According to mean airway/FIO2 chart and recruitment manoeuvres & Adjusting mean airway pressure, then $\mathrm{FIO}_{2}$ \\
\hline Recruitment manoeuvres & $\begin{array}{l}\text { Initiation of HFOV } \\
\text { FIO2 }>0.6 \text { or persistent desaturation } \\
\text { Up to } 4 \text { mandated (in } 24 \mathrm{~h} \text { ), then at clinician discretion }\end{array}$ & Not in algorithm \\
\hline Mean airway pressure & $31(2.6)$ & $26.9(6.2)$ \\
\hline Frequency & $5.5(1)$ & $7.8(1.8)$ \\
\hline APACHE II & $29(8)$ & $21.8(6)$ \\
\hline Mortality & $\begin{array}{l}40 \%<28 \text { days } \\
47 \% \text { in hospital }\end{array}$ & $41.1 \%$ at 30 days \\
\hline \multirow[t]{3}{*}{ Conventional Ventilation } & OSCILLATE & OSCAR \\
\hline & 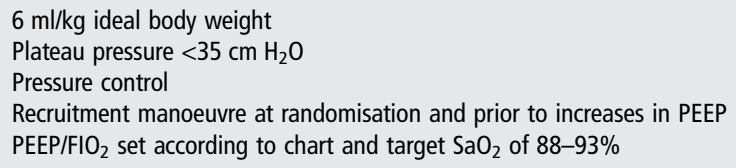 & $\begin{array}{l}\text { Encouraged to use } 6-8 \mathrm{ml} / \mathrm{kg} \text { ideal body weight } \\
\text { PEEP and } \mathrm{FIO}_{2} \text { according to ARDSNet strategy }\end{array}$ \\
\hline & Strictly protocolised & Local practice \\
\hline Tidal volume & $6.1(1.3)$ & $8.3(2.9)$ \\
\hline PEEP & $18(3.2)$ & $11.4(3.6)$ \\
\hline Plateau & $32(5.7)$ & $30.9(11)$ \\
\hline APACHE II & $29(7)$ & $21.7(6.1)$ \\
\hline Mortality & $\begin{array}{l}29 \%<28 \text { days } \\
35 \% \text { in hospital }\end{array}$ & $41.1 \%$ at 30 days \\
\hline
\end{tabular}

ARDS, acute respiratory distress syndrome; HFOV, high-frequency oscillatory ventilation. 
ideal body weight, the two arms would not have demonstrated equivalently. In OSCILLATE, more patients in the intervention group required vasoactive drugs and required them for a longer duration, possibly due to the high inflation pressures and frequent recruitment manoeuvres associated with the protocol and perhaps a less aggressive recruitment strategy would have mitigated this.

\section{CONCLUSION}

These two studies ${ }^{7}{ }^{8}$ reinforce the importance of conventional lung protective ventilation in managing patients in ARDS. They also beg the question of why HFOV was not shown to be beneficial when one considers this mode of ventilation might be considered an optimal protective strategy. Data suggest that tidal volumes lower than $6 \mathrm{ml} / \mathrm{kg}$ (such as those that can be achieved with HFOV) are advantageous. ${ }^{15} 16$ However, measuring tidal volume during HFOV is not a feature of standard oscillators and larger tidal volumes than anticipated may be delivered. ${ }^{17}$ In addition to reducing frequency and increasing amplitude, larger endotracheal tube (ETT) size may be an important variable in increasing tidal volumes delivered to patients. ${ }^{17}$ The OSCAR trial recommended that the ETT tube was changed for one with a larger diameter. Importantly, the OSCILLATE protocol aimed for a maximal amplitude and adjusted $\mathrm{pH}$ with as high a frequency as possible over the range $3-12 \mathrm{~Hz}$. However, on day 1, frequency was $5.5 \mathrm{~Hz}$ (SD 0.97), and it is possible that delivered tidal volumes were larger than the study hoped to achieve.

Ventilator settings for HFOV have largely developed by trial and error and although one of the two trials ${ }^{8}$ used a protocol based on expert opinion; ${ }^{11}$ this has not been validated in other studies. HFOV is a complex intervention ${ }^{10}$ that requires experience and expertise. High inflation pressures and frequent recruitment manoeuvres may have led to increased haemodynamic compromise. When HFOV is initiated, there may be significant effects on preload, afterload, pulmonary vascular resistance, ventricular function and cardiac output. ${ }^{18}$ Avoidance of overdistension of lung, judicious use of fluids, sedatives and vasoactive drugs are all important aspects of patient management acquired through experience of using HFOV.
Which way at the crossroads for HFOV? The results of OSCAR and OSCILLATE will be a disappointment for proponents of HFOV; however, it is too early to abandon this therapy from the armamentarium of ARDS strategies. Future studies should focus on selection of patients likely to benefit from this intervention and on careful titration of mean airway pressures probably without sustained high inflation pressure recruitment manoeuvres. ${ }^{19} 20$ Novel techniques of measuring recruitment such as electrical impedance tomography, ultrasound, bedside CT scanning, transpulmonary pressure, or inflammatory cytokines may have a role to play in optimising recruitment and tidal volumes while minimising adverse effects on cardiac function.

Contributors All authors contributed equally to the manuscript.

Competing interests MW was involved in recruitment of patients to OSCAR and was a local investigator for OSCILLATE, although the study was terminated before any patients were recruited. MW has been loaned an electrical impedance tomography device for research purposes by CareFusion. MW has also provided clinician feedback on ventilator interfaces to Carefusion. AGS and MAG have no conflicts of interest to declare.

Provenance and peer review Not commissioned; internally peer reviewed.

To cite Wise MP, Saayman AG, Gillies MA. Thorax 2013;68:406-408.

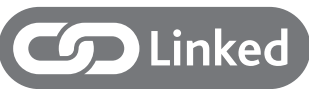

http://dx.doi.org/10.1136/thoraxjnl-2013-203455

Thorax 2013;68:406-408

doi:10.1136/thoraxjnl-2013-203466

\section{REFERENCES}

1 Ashbaugh DG, Bigelow DB, Petty TL, et al. Acute respiratory distress in adults. Lancet 1967;2:319-23.

2 ARDS Definition Task Force, Ranieri VM, Rubenfeld $\mathrm{GD}$, Thompson BT, et al. Acute respiratory distress syndrome: the Berlin Definition. JAMA 2012;307:2526-33.

3 Villar J, Kacmarek RM. The American-European Consensus Conference definition of the acute respiratory distress syndrome is dead, long live positive end-expiratory pressure! Med Intensiva 2012;36:571-5.

4 The Acute Respiratory Distress Syndrome Network. Ventilation with lower tidal volumes as compared with traditional tidal volumes for acute lung injury and the acute respiratory distress syndrome. $N$ Engl J Med 2000;342:1301-8.

5 Derdak S, Mehta S, Stewart TE, et al. Multicenter Oscillatory Ventilation For Acute Respiratory Distress Syndrome Trial (MOAT) Study Investigators. High-frequency oscillatory ventilation for acute respiratory distress syndrome in adults: a randomized, controlled trial. Am J Respir Crit Care Med 2002;166:801-8.
6 Bollen CW, van Well GT, Sherry T, et al. High frequency oscillatory ventilation compared with conventional mechanical ventilation in adult respiratory distress syndrome: a randomized controlled trial [ISRCTN24242669]. Crit Care 2005;9:R430-9.

7 Young D, Lamb S, Shah S, et al. for the OSCAR study group. High-frequency oscillation for acute respiratory distress syndrome. NEJM 2013, Epub ahead of print 22nd January 2013, doi:10.1056/ NEJMoa1215716

8 Ferguson ND, Cook DJ, Guyatt GH, et al. for the OSCILLATE trial investigators and the Canadian Critical Care Trials Group. High-frequency oscillation in early acute respiratory distress syndrome. NEJM 2013; Epub ahead of print 22nd January 2013, doi:10.1056/NEJMoa1215554

9 Kahn JM, Goss CH, Heagerty PJ, et al. Hospital volume and the outcomes of mechanical ventilation. N Engl J Med 2006;355:41-50.

10 Chiche JD, Angus DC. Testing protocols in the intensive care unit: complex trials of complex interventions for complex patients. JAMA 2008;299:693-5.

11 Fessler HE, Derdak S, Ferguson ND, et al. A protocol for high-frequency oscillatory ventilation in adults: results from a roundtable discussion. Crit Care Med 2007:35:1649-54.

12 Meade MO, Cook DJ, Guyatt GH, et al. Lung Open Ventilation Study Investigators. Ventilation strategy using low tidal volumes, recruitment maneuvers, and high positive end-expiratory pressure for acute lung injury and acute respiratory distress syndrome: a randomized controlled trial. JAMA 2008;299:637-45.

13 Needham DM, Colantuoni E, Mendez-Tellez PA, et al. Lung protective mechanical ventilation and two year survival in patients with acute lung injury: prospective cohort study. BMJ 2012;344:e2124.

14 Peek GJ, Mugford M, Tiruvoipati R, et al. Efficacy and economic assessment of conventional ventilatory support versus extracorporeal membrane oxygenation for severe adult respiratory failure (CESAR): a multicentre randomised controlled trial. Lancet 2009;374:1351-63.

15 Retamal J, Libuy J, Jimenez $M$, et al. Preliminary study of ventilation with $4 \mathrm{ml} / \mathrm{kg}$ tidal volume in acute respiratory distress syndrome: feasibility and effects on cyclic recruitment-derecruitment and hyperinflation. Crit Care 2013;17:R16.

16 Capoluongo E, Vento G, Santonocito C, et al. Comparison of serum levels of seven cytokines in premature newborns undergoing different ventilatory procedures: high frequency oscillatory ventilation or synchronized intermittent mandatory ventilation. Eur Cytokine Netw 2005;16:199-205.

17 Hager DN, Fessler HE, Kaczka DW, et al. Tidal volume delivery during high-frequency oscillatory ventilation in adults with acute respiratory distress syndrome. Crit Care Med 2007;35:1522-9.

18 David M, von Bardeleben RS, Weiler N, et al. Cardiac function and haemodynamics during transition to high-frequency oscillatory ventilation. Eur J Anaesthesiol 2004;21:944-52.

19 Halbertsma FJ, Vaneker M, Pickkers $\mathrm{P}$, et al. A single recruitment maneuver in ventilated critically ill children can translocate pulmonary cytokines into the circulation. J Crit Care 2010;25:10-15.

20 Mekontso Dessap A, Voiriot G, Zhou T, et al. Conflicting physiological and genomic cardiopulmonary effects of recruitment maneuvers in murine acute lung injury. Am J Respir Cell Mol Biol 2012;46:541-50. 